\title{
Microencapsulation of steviol glycosides (Stevia rebaudiana Bertoni) by a spray drying method - Evaluation of encapsulated products and prepared syrups
}

\author{
Charikleia Chranioti $^{\mathrm{a}}$, Sofia Chanioti ${ }^{\mathrm{a}}$, And Constantina Tzia ${ }^{{ }^{*}}$ \\ ${ }^{\text {a }}$ Laboratory of Food Chemistry and Technology, School of Chemical Engineering, National Technical \\ University of Athens, Greece \\ ${ }^{*}$ Corresponding author \\ tzia@chemeng.ntua.gr \\ TEL: $+30-210 / 772-3165$ \\ FAX: $+30-210 / 772-3163$
}

Received: 18 July 2014; Published online: 18 October 2015

Invited paper from the $3^{\text {rd }}$ International ISEKI_Food Conference - ISEKI_Food 2014 - Bridging Training and Research for Industry and the Wider Community - Food Science and Technology Excellence for a Sustainable Bioeconomy

\begin{abstract}
The aim of this study was to encapsulate the steviol glycosides (SGs), derived from Stevia rebaudiana (Bert) Bertoni leaves, by applying a spray-drying method. The purpose was to minimize the bitter aftertaste of the SGs as well as to ameliorate/improve their properties. The encapsulation agents used were maltodextrin (19 DE) and inulin in a ratio of $80: 20$, while three levels of SGs in total solids (1.5, 2.5 and $3.5 \%$ ) were studied. The encapsulated SGs products were evaluated for their hygroscopicity, solubility, moisture content and microencapsulation efficiency (MEE \%). Also, syrups prepared with encapsulated SGs, at $1 \% \mathrm{w} / \mathrm{v}$, were tested for their viscosity, refractive index, turbidity and sensory properties. Significant differences $(\mathrm{P}<0.05)$ in MEE \%, moisture content, hygroscopicity and solubility values of the encapsulated SGs products were observed depending on the level of SGs in total solids. In particular, the MEE \%, the hygroscopicity and the solubility values ranged from $62.36,82.46$ to 94.67 $\%, 21.51,26.67$ and $24.25 \%$ and 99.93, 97.50 to $96.03 \%$ for encapsulated SGs products produced with 1.5, 2.5 and $3.5 \%$ SGs in total solids, respectively. The encapsulated product produced with $2.5 \%$ steviol glycosides in total solids presented the most appealing sensory and quality characteristics.
\end{abstract}

Keywords: Microencapsulation; Spray drying; Sweetener; Steviol glycosides; HPLC; Sensory evaluation

\section{Introduction}

In recent years, interest has grown in the sweet steviol glycosides extracted from leaves of Stevia rebaudiana (Bert) Bertoni which can be used as alternatives to sugar. Steviol glycosides, compared to other synthetic sweeteners such as aspartame, saccharine, sucralose and acesulfame$\mathrm{K}$ that are often regarded as either having an undesirable aftertaste or being linked to health concerns, can be a natural alternative sweetener (Hearn \& Subedi, 2009; Guggisberg, Piccinali, \& Schreier, 2011).

Stevia rebaudiana is a plant native from Paraguay and has been used as a herbal sweetener for a long time. Extracts derived from Stevia rebaudiana leaves show great potential as they are heat-stable and non-caloric, assist den- 
tal health by reducing the intake of sugar, open the possibility for use by phenylketonuria patients and obese persons, treat hypoglycaemia, candidasis, high blood pressure, and skin abrasions, and inhibit growth and reproduction of bacteria-like plaque (Geuns, 2003; Alupului, Calinescu, \& Lavric, 2009). Moreover, steviol glycosides (SGs) possess additional health benefits, as they can boost insulin production by pancreatic beta cells and increase glucose tolerance, thus being a suitable option for type II diabetics (Puri, Sharma, \& Tiwari, 2011; Lemus-Mondaca, VegaGalvez, Zura-Bravo, \& Ah-Hen, 2012).

The sweetness of Stevia rebaudiana is mainly attributed to two glycoside compounds: stevioside (4-13\% of dry leaf weight) and rebaudioside A (2 - $4 \%$ ) which can be up to 200-300 times sweeter than sucrose (Garcia-Noguera, Weller, Oliveira, Rodrigues, \& Fernandes, 2010). However, the sensorial and physicochemical properties of these glycosides differ from one another. Rebaudioside A, which has an extra glucose unit relative to stevioside, is superior in terms of both sweetness and quality of taste, whereas pure stevioside usually produces a significant bitter aftertaste. The native ratio of stevioside: rebaudioside-A found in leaves of Stevia rebaudiana is usually about 2 and as a result, stevioside confers a characteristic bitter aftertaste to the extracts (Dacome et al., 2005; Lemus-Mondaca et al., 2012).

Nevertheless, steviol glycosides are unsuitable for use in food applications involving heating (such as baking, sterilisation and frying) or a controlled release of the sweet taste, since part of the molecule may undergo hydrolysis leading to a loss of sweet taste. In the case of sweeteners, microencapsulation is typically used to provide protection by offering resistance to high temperatures, to increase their fluidity and to prolong the sensation of sweetness by controlling their release (Loksuwan, 2007; Rocha-Selmi, Bozza, Thomazini, Bolini, \& Favaro-Trindade, 2013). The microencapsulation process basically consists of the preparation of an emulsion or dispersion that contains the encapsulating agent and the core material (sweetener), which is then dried, commonly using spray or freezedrying techniques (Lim, Tan, Bakar, \& Ng, 2012). Spray-drying is the most usual method for this purpose as it has a lower processing cost than freeze-drying (Dzondo-Gadet, Nzikou, Etoumongo, Linder, \& Desobry, 2005).

The selection of the encapsulation agent is very crucial for an efficient encapsulation (Gharsallaoui, Roudaut, Chambin, Voilley, \& Saurel, 2007). Materials used in the food industry as encapsulating agents are classified into three major categories, namely carbohydrate polymers, proteins and lipids, where carbohydrate polymers are the most widely used (Sansone et al. 2011; Murugesan \& Orsat, 2012). Among them, maltodextrins are widely used as encapsulation agents (Reineccius, 1988), since they possess a good compromise between cost and effectiveness (Apintanapong \& Noomhorm, 2003). Maltodextrins are produced by partial hydrolysis of starch with acid or enzymes, and they have the advantage of being low cost, while offering protection to flavour and fat by reducing oxygen permeability of the wall matrix. In addition, the storage stability of core materials increases as the maltodextrin dextrose equivalent (DE) increases (Anandaraman \& Reineccius, 1987). Therefore, maltrodextrin is an efficient and stable agent for encapsulation of natural products (Loksuwan, 2007; Sansone et al., 2011; Wang \& Zhou, 2012). Inulin, a mixture of oligo- and polysaccharides, is of great interest since it is often used as a bulking agent in the production of sugar-free products, and has an additional advantage of being a dietary fibre (Zahn, Forker, Kruegel, \& Rohm, 2013). The application of a spray-drying technique and the use of maltodextrin as the encapsulation agent can result in temperature resistant products which provide excellent characteristics for controlled release of a sweet taste (Sansone et al., 2011; Rocha-Selmi et al., 2013). These features are fundamental to achieve the goal of this work, which is to develop a vehicle for progressive release of steviol glycosides thus reducing their bitter aftertaste.

The aim of this study was to encapsulate the steviol glycosides (SGs) of Stevia rebaudiana in order to minimize their bitter aftertaste and ameliorate/improve their properties. Spray-drying was applied as the microencapsulation method, with maltodextrin (19 DE) and inulin as the encapsulating agents and use of three levels of steviol glycosides $(1.5,2.5$ and $3.5 \%$ in total solids). The encapsulated products were evalu- 
ated for hygroscopicity, solubility, moisture content and encapsulation efficiency, while the prepared syrups were tested for viscosity, refractive index, turbidity and sensory properties.

\section{Materials and Methods}

\section{$2.1 \quad$ Materials}

The steviol glycosides (SGs), containing stevioside $(57.12 \%)$ and rebaudioside A $(24.78 \%)$, derived from the plant Stevia rebaudiana Bertoni were generously donated by $\mathrm{NL}^{*}$ Stevia and used as the core material. Inulin, IN, (Fibrulose F97) and maltodextrin, MD, from Waxy Maize (19 DE) were obtained from Astron Chemicals S.A. and Chemicotechnica S.A., respectively and used as the encapsulating agents. Rebaudioside A, RA, (98\% purity) was provided by NL* Stevia and used as a standard. All chemicals used were of analytical reagent (AR) grade.

\subsection{Production of the spray-dried products}

The methodology for production of the encapsulated products by spray drying is presented in Figure 1. First, the encapsulating agents of inulin and maltodextrin (19 DE) were dispersed at $65{ }^{\circ} \mathrm{C}$ for 15 min under constant stirring. Then, steviol glycosides (SGs) were added and mixed, using an homogenizer (Unidrive X 1000, CAT) for $5 \mathrm{~min}$ at 10,000 rpm (Ortiz et al., 2009; Chranioti \& Tzia, 2013), until complete dispersion of the solids was achieved. The resulting dispersion was fed to a laboratory spray dryer with a two fluid nozzle (B-191, Büchi Mini Spray Drier) which was operated under the following conditions: inlet air temperature $\left(\mathrm{T}_{i n}\right): 160{ }^{\circ} \mathrm{C}$, outlet air temperature $\left(\mathrm{T}_{\text {out }}\right): 88^{\circ} \mathrm{C}$, feed temperature: $60{ }^{\circ} \mathrm{C}$, air pressure: 5 bar, aspirator: $90 \%$, pump: $40 \%$ and compressed air flow rate: $500 \mathrm{~L} / \mathrm{h}$. The products in powdered form were collected at the bottom of the dryer's cyclone and were stored in glass bottles, which were held at room temperature, in a dry place, in the absence of light. Three formulations with different concentrations of SGs were examined: A: $1.5 \%$, B:
$2.5 \%$ and C: $3.5 \%$, while the ratio of maltodextrin to inulin (MD : IN) was maintained constant at 80: 20 in all formulations (Table 1).

\subsection{Analyses of encapsulated products}

\section{Moisture Content}

The moisture content of the encapsulated products, the encapsulating agents (maltodextrin and inulin), and the sweeteners, steviol glycosides and sugar, was determined gravimetrically by oven drying at $100{ }^{\circ} \mathrm{C}$ to a constant weight (AOAC, 1973).

\section{Solubility}

$1 \mathrm{~g}$ of each sample was added to beakers containing $100 \mathrm{~mL}$ of distilled water, and stirred at $110 \mathrm{rpm}$ for $30 \mathrm{~min}$, before centrifuging at $4000 \mathrm{rpm}$ for $5 \mathrm{~min}$. Aliquots of each supernatant were then removed, transferred to previously weighed porcelain dishes, and dried to constant weight in an incubator at $100{ }^{\circ} \mathrm{C}$. The dishes were weighed and the solubility was calculated from the difference in weight (CanoChauca, Stringheta, Ramos, \& Cal-Vidal, 2005).

\section{Hygroscopicity}

Approximately $1 \mathrm{~g}$ of each sample was placed in hermetic pots containing a saturated sodium sulphate solution (relative humidity of $81 \%$ ) and weighed again after 7 days. The hermetic pots were kept at $25{ }^{\circ} \mathrm{C}$ in an incubator, with controlled temperature. The hygroscopicity was expressed as grams of water absorbed by $100 \mathrm{~g}$ of sample (Cai \& Corke, 2000).

\section{Microencapsulation efficiency (MEE $\%)$}

The microencapsulation efficiency (MEE \%) of the spray dried products was based on their rebaudioside A (RA) content and calculated according to Rocha-Selmi et al. (2013), as shown in equation 1 .

$$
M E E \%=\frac{\text { encapsulated RA }}{\text { initial RA }} \times 100
$$




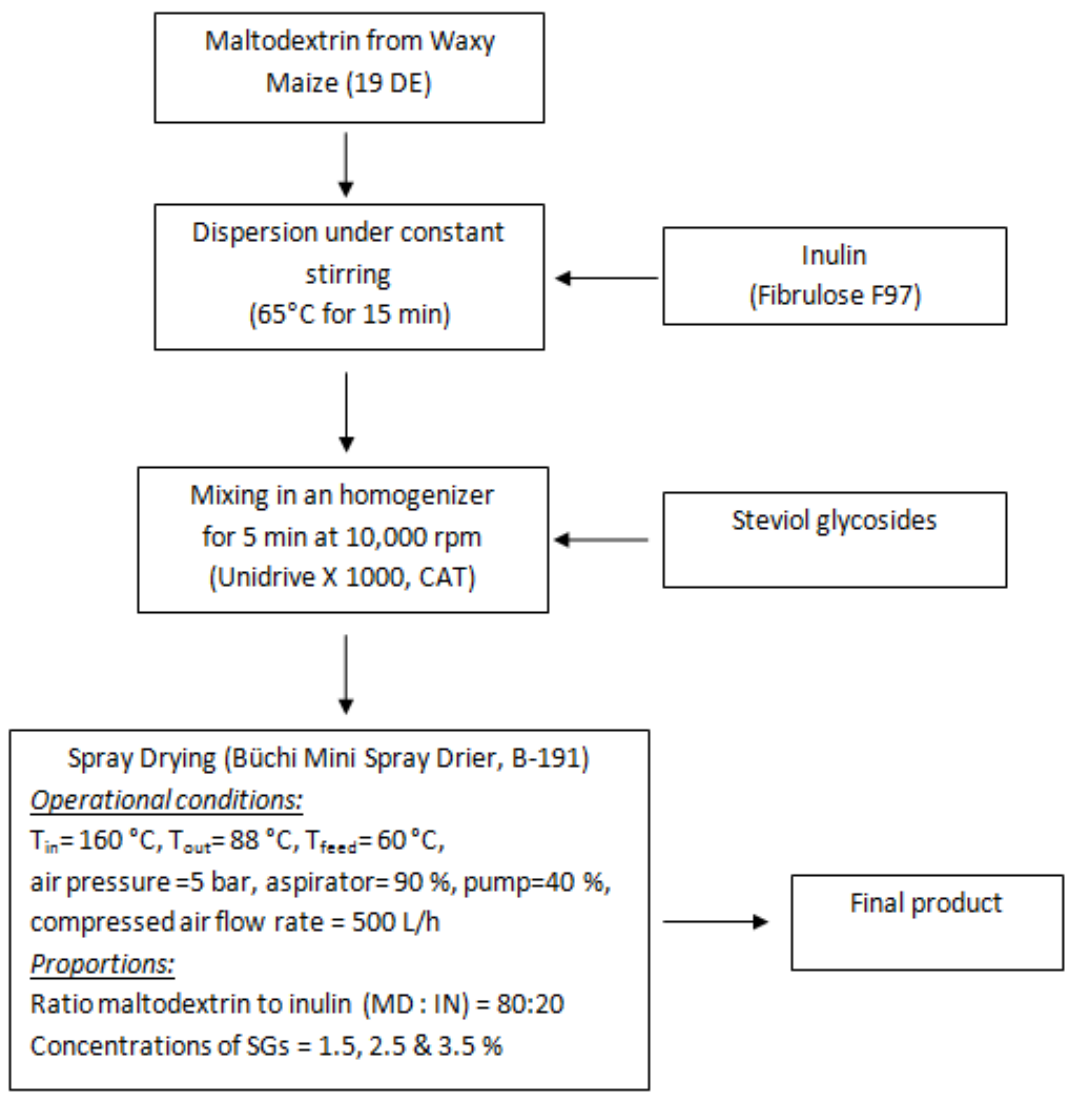

Figure 1: Flow diagram of microencapsulation process of stevia glycosides (SG)

Table 1: Properties of the encapsulated steviol glycosides products

\begin{tabular}{ccccc}
\hline Sample $^{a}$ & ${\text { MEE } \%^{b}}^{b}$ & Moisture content \% & Solubility \% & Hygroscopicity \\
\hline A & $62.36 \pm 1.80^{a}$ & $7.19 \pm 0.21^{c}$ & $99.93 \pm 0.12^{f}$ & $21.51 \pm 0.13^{a}$ \\
B & $82.46 \pm 1.60^{b}$ & $7.99 \pm 0.04^{d}$ & $97.50 \pm 0.10^{e}$ & $26.67 \pm 0.18^{d}$ \\
C & $94.67 \pm 1.93^{c}$ & $6.89 \pm 0.13^{b}$ & $96.03 \pm 0.03^{d}$ & $24.25 \pm 0.20^{b}$ \\
MD & - & $6.28 \pm 0.03^{a}$ & $88.21 \pm 0.10^{c}$ & $24.95 \pm 0.09^{c}$ \\
IN & - & $19.9 \pm 0.07^{e}$ & $76.32 \pm 0.08^{b}$ & $53.06 \pm 0.11^{e}$ \\
SG & - & $41.5 \pm 0.12^{f}$ & $62.46 \pm 0.09^{a}$ & $89.22 \pm 0.07^{f}$ \\
\hline
\end{tabular}

${ }^{a}$ A: $1.5 \%$, B: $2.5 \%$ and C: $3.5 \%$ in steviol glycosides.

$b$ MEE \%: microencapsulation efficiency (\%)

Means within the same column, followed by different letters (a, b, c, d, e, f) are significantly different $(P<0.05)$

IJFS | October 2015 | Volume 4 | pages 212-220 


\section{HPLC analysis}

For the quantification of the RA, a HP 1100 Series gradient HPLC system (Agilent Technologies, USA) combined with quaternary pump, diode array detector (Hewlett-Pachard, Waldbronn, Germany) and data analysis software (ChemStation for LC3D Software, Agilent Technologies, Waldbronn, Germany) was employed. A column $(250 \times 4.6 \mathrm{~mm})$ packed with $5 \mu \mathrm{m}$ particles Hypersil C18 (MZ Analysentechnik, Mainz, Germany) was used for the separation. The operating conditions for HPLC analysis were as follows: ambient temperature, acetonitrile-water (80: 20) as the eluting solvent at a flow rate of $1 \mathrm{~mL} / \mathrm{min}$ and wavelength of UV detector, 210 nm.

The standard curve of RA was prepared using concentrations of RA between 0.05 and 0.3 $\mathrm{mg} / \mathrm{mL}$. The standard curve was analysed using the linear least-squares regression equation derived from the peak area (regression equation y $=5,000,000 \mathrm{x}+93.27, \mathrm{r}=0.998$ where $\mathrm{y}$ is the peak area and $\mathrm{x}$ the concentration).

\section{Sample preparation}

To determine the encapsulated RA present in the products, $1 \mathrm{~g}$ of the sample was placed in a $20 \mathrm{~mL}$ screw cap test tube and was extracted by vortex mixing for $10 \mathrm{~min}$, at ambient temperature, with $10 \mathrm{~mL}$ of $1: 1$ ethanol/water. The tube was subsequently centrifuged at $5000 \mathrm{rpm}$ for $5 \mathrm{~min}$ and an aliquot of the supernatant was filtered through a $0.45 \mu \mathrm{m}$ PTFE filter and used for quantification of the RA.

\subsection{Syrup analyses}

Syrups were prepared with the encapsulated SGs in water at $1 \% \mathrm{w} / \mathrm{v}$. The so-prepared syrups were tested for viscosity, refractive index and turbidity. Sensory evaluation was also conducted.

\section{Viscosity}

Viscosities of the syrups were measured using Brookfield DV-II + Pro viscometer at $25^{\circ} \mathrm{C}$ with a sample volume of $50 \mathrm{~mL}$ operating at $100 \mathrm{rpm}$ using a spindle set of S61 (Kshirsagar, Yenge, Sarkar, \& Singhal, 2009).

\section{Refractive index}

The refractive index of the syrups was determined in visible light, using a refractometer BOE 32400 ABBE, Boeco, Germany; range of measurement: $1.300-1.700$, accuracy: \pm 0.0002 . The measurements were carried out at ambient temperature (Polychniatou \& Tzia, 2014).

\section{Turbidity}

The turbidity of the syrups was measured by a Turbimeter (Hach 2100 N, Loveland, Co, USA). For the measurement, $20 \mathrm{~mL}$ of the samples were poured into a glass cell while the temperature was set at $25^{\circ} \mathrm{C}$. The values of turbidity are given in NTU (Nephelometric Turbidity Units) which are the most common turbidity units.

\section{Sensory evaluation}

The sensory evaluation of the encapsulated SGs products, in the form of syrups, was carried out in the accredited (ISO 17025) sensory laboratory of NTUA, which is equipped with individual booths. The panellists had been trained in sensory analysis and had former experience in assessing sweetener samples. The evaluation of the spray dried products was carried out according to the literature (Pangborn, 1963; Parpinello, Versari, Castellari, \& Galassi, 2001; Ye et al., 2013) with some modifications. In particular, the samples of encapsulated SGs products were dissolved in drinking water and diluted to a concentration of $1 \mathrm{~g} / 100 \mathrm{~mL}$, while sucrose as well as SGs were prepared with concentrations of 10 and $1 \mathrm{~g} / 100 \mathrm{~mL}$, respectively, and used as controls. The samples were served as $100 \mathrm{~mL}$ aliquots in $300 \mathrm{~mL}$ odour-free paper cups at room temperature $\left(25^{\circ} \mathrm{C}\right)$ and analyses were performed in individual tasting booths under normal lighting conditions. Panellists were instructed to rinse their palates between samples. The evaluated parameters were sweet intensity, bitter aftertaste and overall acceptance while the score scale applied was $0(\min )-5(\max )$ for sweet intensity and 0 


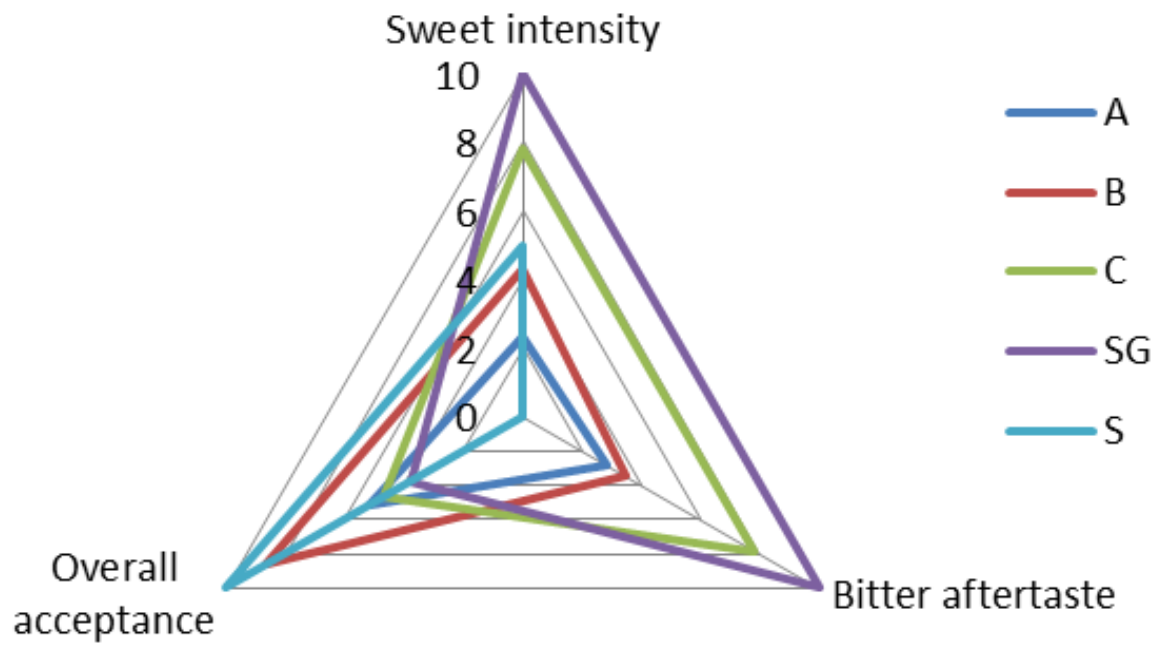

Figure 2: Sensory evaluation of syrups prepared from encapsulated steviol glycosides products

Table 2: Properties of syrups prepared from encapsulated steviol glycosides products, measured at $25^{\circ} \mathrm{C}$

\begin{tabular}{cccc}
\hline Sample $^{a}$ & Viscosity (mPa·s) & Refractive index (Brix) & Turbidity (NTU) \\
\hline A & $2.90 \pm 0.03$ & $0.80 \pm 0.00$ & $3.67 \pm 0.58$ \\
B & $3.02 \pm 0.13$ & $1.10 \pm 0.00$ & $2.67 \pm 0.58$ \\
C & $2.88 \pm 0.18$ & $1.00 \pm 0.00$ & $4.00 \pm 1.73$ \\
\hline
\end{tabular}

${ }^{a}$ A: $1.5 \%$, B: $2.5 \%$ and C: $3.5 \%$ in steviol glycosides

$(\min )-10(\max )$ for bitter aftertaste and overall acceptance, respectively.

\subsection{Statistical analysis}

The experiments were carried out in triplicate. The resulting data was assessed by analysis of variance (ANOVA) using STATISTICA 7 (Statsoft Inc., Tulsa, USA). Duncan's test was used for significant differences at the probability level $\mathrm{P}<0.05$.

\section{Results and Discussion}

\subsection{Characterization of encapsulated products}

The microencapsulation efficiency (MEE \%) varied from $62.36,82.46$ to $94.67 \%$ for A, B and C formulations, respectively (Table 1). Increasing the steviol glycosides content resulted in a higher MEE \%. Significant differences $(\mathrm{P}<0.05)$ in the MEE \% values of the encapsulated SGs products were observed at the different SGs levels in total solids.

The moisture content values were within the expected range for sweetener powdered products $(6.89-7.99 \%)$ as reported by other researchers (Rocha-Selmi et al., 2013).

The spray dried products were found to be less hygroscopic than the un-encapsulated SGs (Table 1). MD which makes up the large majority of the products is less hygroscopic. Therefore, the spray dried products had properties close to the major component. Also, it must be noted that this reduced hygroscopicity could enhance the stability of the products.

The solubility of the encapsulated products was

IJFS | October 2015 | Volume 4 pages 212-220 
raised compared to the un-encapsulated SGs. In particular, the solubility values of the formulations varied from 99.93, 97.50 to $96.03 \%$ for A, $\mathrm{B}$ and $\mathrm{C}$ formulations, respectively, while the unencapsulated SGs solubility value was $62.64 \%$. Similarly, as in $\mathrm{MEE} \%$, significant differences $(\mathrm{P}<0.05)$ in moisture content, hygroscopicity and solubility values of the encapsulated SGs products were observed at the different SGs levels in total solids.

\subsection{Characterization of the produced syrup}

The syrups prepared with the encapsulated SGs in water at $1 \% \mathrm{w} / \mathrm{v}$ presented no significant differences in viscosity, refractive index and turbidity with respect to the SGs levels in total solids (Table 2).

In sensory evaluation, the formulation B with steviol glycosides content $2.5 \%$ in total solids presented the highest overall acceptance (8.67). This sample was perceived as the most appealing sweetener, without overcoming the bitter aftertaste threshold (5) (Figure 2).

\section{Conclusions}

The results of this study show that the application of spray drying, with maltodextrin and inulin as encapsulating agents, is efficient in attenuating or masking the bitter aftertaste of steviol glycosides (SGs) products. The MEE \% ranged between 62.0 to $95.0 \%$ and the resulting encapsulated products presented varied properties, with the sample of $2.5 \%$ SGs level in total solids having the best quality characteristics and the most appealing sensorial ones. Also, the reduced hygroscopicity value contributed to products with improved stability.

\section{Acknowledgements}

Financial support for author C. Chranioti through a scholarship granted by the State Scholarships Foundation is gratefully acknowledged.

\section{References}

Alupului, A., Calinescu, I., \& Lavric, V. (2009). Ultrasonic vs. microwave extraction intensification of active principles from medicinal plants. In AIDIC conference series (Vol. 9, pp. 1-8). doi:10 . 3303/ ACOS0909001

Anandaraman, S. \& Reineccius, G. A. (1987). Analysis of encapsulated orange peel oil. Perfumer \& Flavorist, 12, 33-39.

AOAC. (1973). Official methods of analysis of the association of official analytical chemists. Arlington: Association of Official Analytical Chemists.

Apintanapong, M. \& Noomhorm, A. (2003). The use of spray drying to microencapsulate 2acetyl-1-pyrroline, a major flavour component of aromatic rice. International Journal Of Food Science And Technology, 38(2), 95-102. doi:10.1046/j . 1365-2621 . 2003. 00649.x

Cai, Y. Z. \& Corke, H. (2000). Production and properties of spray-dried amaranthus betacyanin pigments. Journal of Food Science, 65(7), 1248-1252. doi:10.1111/j.1365-2621. 2000.tb10273.x

Cano-Chauca, M., Stringheta, P. C., Ramos, A. M., \& Cal-Vidal, J. (2005). Effect of the carriers on the microstructure of mango powder obtained by spray drying and its functional characterization. Innovative Food Science \& Emerging Technologies, 6(4), 420-428. doi:10.1016/j.ifset. 2005.05 .003

Chranioti, C. \& Tzia, C. (2013). Binary mixtures of modified starch, maltodextrin and chitosan as efficient encapsulating agents of fennel oleoresin. Food and Bioprocess Technology, 6(11), 3238-3246. doi:10.1007/ s11947-012-0966-7

Dacome, A. S., da Silva, C. C., da Costa, C. E. M., Fontana, J. D., Adelmann, J., \& da Costa, S. C. (2005). Sweet diterpenic glycosides balance of a new cultivar of Stevia rebaudiana (bert.) bertoni: isolation and quantitative distribution by chromatographic, spectroscopic, and electrophoretic methods. Process Biochemistry, 40(11), 
3587-3594. doi:10.1016/j.procbio.2005.03. 035

Dzondo-Gadet, A., Nzikou, J. M., Etoumongo, A., Linder, A., \& Desobry, S. (2005). Encapsulation and storage of safou pulp oil in 6de maltodextrins. Process Biochemistry, 40(1), 265-271. doi:10.1016/j . procbio . 2004.01 .013

Garcia-Noguera, J., Weller, C. L., Oliveira, F. I. P., Rodrigues, S., \& Fernandes, F. A. N. (2010). Dual-stage sugar substitution in strawberries with a steviabased sweetener. Innovative Food Science E Emerging Technologies, 11(1), 225-230. doi:10.1016/j.ifset.2009.07.001

Geuns, J. M. C. (2003). Stevioside. Phytochemistry, 64 (5), 913-921. doi:10.1016/S00319422(03)00426-6

Gharsallaoui, A., Roudaut, G., Chambin, O., Voilley, A., \& Saurel, R. (2007). Applications of spray-drying in microencapsulation of food ingredients: an overview. Food Research International, 40(9), 1107-1121.

Guggisberg, D., Piccinali, P., \& Schreier, K. (2011). Effects of sugar substitution with stevia, actilight (tm) and stevia combinations or palatinose (tm) on rheological and sensory characteristics of low-fat and whole milk set yoghurt. International Dairy Journal, 21 (9), 636-644. doi:10.1016/j.idairyj. 2011.03.010

Hearn, L. K. \& Subedi, P. P. (2009). Determining levels of steviol glycosides in the leaves of Stevia rebaudiana by near infrared reflectance spectroscopy. Journal of Food Composition and Analysis, 22(2), 165-168. doi:10.1016/j.jfca.2008.10.008

Kshirsagar, A. C., Yenge, V. B., Sarkar, A., \& Singhal, R. S. (2009). Efficacy of pullulan in emulsification of turmeric oleoresin and its subsequent microencapsulation. Food Chemistry, 113(4), 1139-1145. doi:10.1016/j.foodchem.2008.09.002

Lemus-Mondaca, R., Vega-Galvez, A., ZuraBravo, L., \& Ah-Hen, K. (2012). Stevia rebaudiana bertoni, source of a high-potency natural sweetener: a comprehensive review on the biochemical, nutritional and functional aspects. Food Chemistry, 132(3),
1121-1132. doi:10.1016/j.foodchem.2011. 11.140

Lim, H.-K., Tan, C.-P., Bakar, J., \& Ng, S.-P. (2012). Effects of different wall materials on the physicochemical properties and oxidative stability of spray-dried microencapsulated red-fleshed pitaya (hylocereus polyrhizus) seed oil. Food and Bioprocess Technology, 5(4), 1220-1227. doi:10.1007/ s11947-011-0555-1

Loksuwan, J. (2007). Characteristics of microencapsulated beta-carotene formed by spray drying with modified tapioca starch, native tapioca starch and maltodextrin. Food Hydrocolloids, 21 (5-6), 928-935. Conference on Food Colloids 2006, Montreux, SWITZERLAND, APR 23-26, 2006. doi:10.1016/j.foodhyd.2006.10.011

Murugesan, R. \& Orsat, V. (2012). Spray drying for the production of nutraceutical ingredients-a review. Food and Bioprocess Technology, 5(1), 3-14. doi:10.1007/ s11947-011-0638-z

Ortiz, S. E. M., Mauri, A., Monterrey-Quintero, E. S., Trindade, M. A., Santana, A. S., \& Favaro-Trindade, C. S. (2009). Production and properties of casein hydrolysate microencapsulated by spray drying with soybean protein isolate. LWT-Food Science and Technology, 42(5), 919-923. doi:10. 1016/j.lwt.2008.12.004

Pangborn, R. (1963). Relative taste intensities of selected sugars and organic acidsa. Journal of Food Science, 28(6), 726-733.

Parpinello, G. P., Versari, A., Castellari, M., \& Galassi, S. (2001). Stevioside as a replacement of sucrose in peach race: sensory evaluation. Journal of Sensory Studies, 16(5), 471-484. doi:10.1111/j.1745-459X. 2001. tb00314.x

Polychniatou, V. \& Tzia, C. (2014). Study of formulation and stability of co-surfactant free water-in-olive oil nano- and submicron emulsions with food grade non-ionic surfactants. Journal of the American Oil Chemists Society, 91(1), 79-88. doi:10 . 1007/s11746-013-2356-3

Puri, M., Sharma, D., \& Tiwari, A. K. (2011). Downstream processing of stevioside and its potential applications. Biotechnology 
Advances, 29(6), 781-791. doi:10.1016/j. biotechadv.2011.06.006

Reineccius, G. A. (1988). Spray-drying of food flavors. In G. A. Reineccius \& S. J. Risch (Eds.), Flavour encapsulation (pp. 55-66). ACS Symposium series-American Chemical Society (USA). Washington: American Chemical Society.

Rocha-Selmi, G. A., Bozza, F. T., Thomazini, M., Bolini, H. M. A., \& Favaro-Trindade, C. S. (2013). Microencapsulation of aspartame by double emulsion followed by complex coacervation to provide protection and prolong sweetness. Food Chemistry, 139(14), 72-78. doi:10.1016/j.foodchem.2013.01. 114

Sansone, F., Mencherini, T., Picerno, P., d'Amore, M., Aquino, R. P., \& Lauro, M. R. (2011). Maltodextrin/pectin microparticles by spray drying as carrier for nutraceutical extracts. Journal of Food Engineering, 105(3), 468-476. doi:10.1016/j. jfoodeng.2011.03.004

Wang, W. \& Zhou, W. (2012). Characterization of spray-dried soy sauce powders using maltodextrins as carrier. Journal of Food Engineering, 109(3), 399-405. doi:10.1016/j. jfoodeng.2011.11.012

Ye, F., Yang, R., Hua, X., Shen, Q., Zhao, W., \& Zhang, W. (2013). Modification of stevioside using transglucosylation activity of bacillus amyloliquefaciens alpha-amylase to reduce its bitter aftertaste. LWT-Food Science and Technology, 51(2), 524-530. doi:10.1016/j.lwt.2012.12.005

Zahn, S., Forker, A., Kruegel, L., \& Rohm, H. (2013). Combined use of rebaudioside a and fibres for partial sucrose replacement in muffins. LWT-Food Science and Technology, 50 (2), 695-701. doi:10.1016/j.lwt. 2012.07.026 